BUDGETING : Journal of Business, Management and Accounting

Volume 2, Nomor 2, Januari-Juni 2021

e-ISSN: 2715-2480

p-ISSN: 2715-1913

DOI: https://doi.org/10.31539/budgeting.v2i2.1751

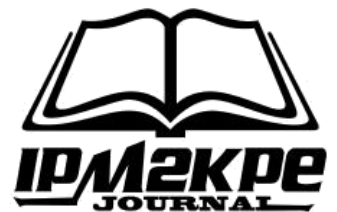

\title{
KEPUTUSAN PEMBELIAN SECARA ONLINE BERDASARKAN KELOMPOK REFERENSI, KELUARGA SERTA PERAN DAN STATUS
}

\author{
Riana Afriansyah ${ }^{1}$, Asep M. Ramdan ${ }^{2}$, Dicky Jhoansyah ${ }^{3}$ \\ Universitas Muhammadiyah Sukabumi ${ }^{1.2 .3}$ \\ afriansyahriana@gmail.com ${ }^{1}$
}

\begin{abstract}
ABSTRAK
Tujuan penelitian ini adalah untuk mengetahui pengaruh kelompok referensi, keluarga serta peran dan status terhadap keputusan pembelian pada pengguna Lazada di Kota Sukabumi. Metode penelitian yang digunakan oleh peneliti dalam penelitian ini adalah menggunakan metode deskriptif kuantitatif dan metode sampel probability sampling dengan melakukan penyebaran kuesioner sebanyak 116 kepada para pengguna Lazada di Kota Sukabumi. Hasil penelitian menunjukkan bahwa hasil uji koefisien determinasi dilihat dari nilai R Square adalah sebesar 0,291. Pengaruh kelompok referensi, keluarga, serta peran dan status terhadap keputusan pembelian secara online pada pengguna Lazada di Kota Sukabumi adalah 29,1\% dan sisanya 70,9\% dipengaruhi oleh faktor lain yang tidak dijelaskan dalam penelitian ini. Kemudian berdasarkan uji koefisien korelasi ganda dapat diketahui dari nilai $\mathrm{R}$ sebesar 0,540 . Berdasarkan uji $\mathrm{f}$ nilai probabilitas Sig. 0,00 < 0,05. Simpulan, secara bersama-sama kelompok referensi, keluarga, serta peran dan status berpengaruh secara signifikan terhadap keputusan pembelian. Adapun untuk hasil uji t, kelompok referensi berpengaruh signifikan terhadap keputusan pembelian, keluarga tidak berpengaruh terhadap keputusan pembelian, sedangkan peran dan status berpengaruh negatif terhadap keputusan pembelian.
\end{abstract}

Kata Kunci: Kelompok Referensi, Keluarga, Keputusan Pembelian, Peran, Status

\section{ABSTRACT}

This study aimed to determine the effect of reference groups, family, and their roles and status on purchasing decisions of Lazada users in Sukabumi City. The researchers' research method in this study is to use descriptive quantitative methods and sample probability sampling methods by distributing 116 questionnaires to Lazada users in Sukabumi City. The results showed that the coefficient of determination test results seen from $R$ Square's value amounted to 0.291. The influence of the reference group, family, and the role and status of online purchasing decisions for Lazada users in Sukabumi City is $29.1 \%$. The remaining $70.9 \%$ is influenced by other factors not explained in this study and then based on the multiple correlation coefficient tests. It can be seen from the R-value of 0.540. Based on the f test, the probability value of Sig. $0.00<0.05$. In conclusion, collectively, the reference group, family, and role and status significantly influence purchasing decisions. As for the t-test results, the reference group has a significant effect on purchasing decisions. The family does not affect purchasing decisions, while role and status have a negative effect on purchasing decisions.

Keywords: Reference Group, Family, Purchasing Decision, Role, Status 


\section{PENDAHULUAN}

Keputusan pembelian merupakan salah satu hal yang tidak dapat dipisahkan dari keseharian konsumen. Menilik kepada hasil survey yang dilakukan oleh Asosiasi Pengguna Jaringan Internet Indonesia (2017), melaporkan bahwa dari 262 juta orang penduduk Indonesia, 143,26 juta jiwa diantaranya adalah pengguna internet dengan presentase sebesar 54,68\%. Survey lain yang dilakukan oleh Globalwebindex (2018) menunjukan bahwa $60 \%$ dari pengguna internet di Indonesia pernah berkunjung ke online shop tokopedia dan $61 \%$ lainnya pernah berkunjung ke Lazada, Bukalapak dan Shoppe. Adapun survey satu tahun sebelumnya didapatkan informasi bahwa rata-rata waktu yang dihabiskan oleh responden orang Indonesia untuk mengakses internet sebanyak 8 jam 51 menit dalam sehari mengalahkan saluran pemasaran yang lain. Masih menurut laporan yang sama bahwa Indonesia menempati urutan ke-4 yang paling gemar online. Hal ini meyakinkan peneliti bahwa penelitian perilaku membeli online menjadi sangat penting dan akan semakin penting dimasa-masa yang akan datang.

Ada beberapa faktor yang mempengaruhi keputusan pembelian oleh konsumen, salah satunya adalah faktor sosial yang didalamnya kelompok referensi, keluarga serta peran sosial dan status memiliki andil dan pengaruh terhadap perilaku pembelian (Kotler \& Keller, 2012). Telah menjadi suatu keharusan bagi konsumen untuk mempertimbangkan segala hal dalam melakukan pembelian baik secara konvensional maupun secara online.

Lazada.co.id merupakan bagian dari Lazada Group yang menjadi tujuan belanja online di Asia Tenggara. Lazada Group beroperasi di Indonesia, Malaysia, Filipina, Singapura, Thailand dan Vietnam. Lazada.co.id merupakan anak perusahaan dari Rocket Internet asal Jerman yang sukses menciptakan banyak produk online inovatif di dunia. Lazada merupakan jaringan e-commerce yang cukup berpengaruh di Asia Tenggara Khususnya di Indonesia. Lazada tumbuh jadi perusahaan besar setelah JP Morgan dan beberapa partner lain ikut mempercayakan investasi pada Lazada dan perusahaan induknya, Rocket Internet (Mauludiyawati, 2017).

Berdasarkan studi terbaru Peta e-commerce iPrice pada kuartal keempat 2018, Lazada masih mampu mempertahankan di posisi puncak sebagai marketplace dengan pengunjung terbanyak, yakni mencapai 117,57 juta pengunjung dengan rata-rata transaksi tercatat 1,6 triliun dalam setiap bulannya. Sementara Tokopedia berada di 
urutan kedua dengan 117,3 juta pengunjung dalam tiga bulan terakhir tahun 2018 . Diposisi ketiga diikuti Bukalapak dengan 53,59 juta pengunjung dan selanjutnya menyusul Blibli dengan jumlah 45,9 juta pengunjung, Shoppe masih di angka 34,5 juta pengunjung, JD.ID 13,2 juta pengunjung, Bhineka 7,4 juta pengunjung, Elevenia 6,3 juta pengunjung, Zalora 5,2 juta pengunjung dan diperingkat terakhir Mataharimall 4 juta pengunjung (Databoks.katadata.co.id, 2018).

Melihat data di atas jumlah pengguna Lazada yang begitu besar tidak lantas kemudian tidak ada masalah yang terjadi di dalamnya. Laporan terakhir dari YLKI (Yayasan Lembaga Konsumen Indonesia) dalam CNBC Indonesia (2018) bahwa Lazada berada di peringkat satu e-commerce yang paling banyak memiliki masalah. Kontribusi pengaduannya mencapai $16 \%$ dari total 642 pengaduan yakni kurangnya informasi dan keterangan yang diberikan oleh Lazada terkait produk-produk barang maupun jasa yang di jual di dalamnya.

Sebagian konsumen mengeluhkan karena kurangnya informasi mengenai produk yang akan dibeli diantaranya kurangnya informasi mengenai deskrispi produk dan penjelesan lengkap mengenai barang atau jasa yang ditawarkan oleh aplikasi dan bahkan tidak sedikit merchant yang tidak menyertakan gambar yang jelas pada aplikasi sehingga dengan begitu konsumen terpaksa untuk mencari informasi di luar aplikasi, dengan menggunakan Google Search Engine. Sebanyak 36\% pengguna Lazada memberikan feedback berupa masukan untuk memberikan informasi dan keterangan yang jelas terhadap toko online serta produk yang ada di dalamnya.

Peneliti menduga bahwa konsumen yang tetap melakukan pembelanjaan secara online karena adanya faktor dorongan dari lingkungan sosial, seperti mendapatkan rekomendasi dari teman yang sudah atau sering melakukan pembelanjaan secara online, melihat dan mengamati pengalaman orang lain dalam melakukan pembelanjaan secara online. Dengan demikian melihat fenomena-fenomena yang terjadi, peneliti sangat tertarik untuk melakukan penelitian mengenai faktor sosial dan pengaruhnya terhadap keputusan pembelian secara online pada pengguna Lazada di Kota Sukabumi. 


\section{KAJIAN TEORI}

\section{Kelompok Referensi}

Kelompok acuan (reference group) adalah seorang individua tau kelompok orang yang secara nyata mempengaruh perilaku seseorang (Schiffman \& Kanuk 2010). Kelompok acuan digunakan oleh seseorang sebagai dasar untuk perbandingan atau sebuah referensi dalam membentuk respon afektif, kognitif dan perilaku. Kelompok acuan akan memberikan standar dan nilai yang akan mempengaruhi perilaku seseorang. Dalam perspektif pemasaran, kelompok acuan adalah kelompok yang berfungsi sebagai referensi bagi seseorang dalam keputusan pembelian dan konsumsi (Sumarwan, 2014).

Kelompok acuan diklasifikasikan ke dalam beberapa jenis diantaranya sebagai berikut:

\section{Kelompok Formal dan Informal}

Kelompok acuan sering dibedakan ke dalam formal dan informal. Kelompok formal adalah kelompok yang memiliki struktur organisasi secara tertulis dan keganggotaan yang terdaftar secara resmi, misalnya Serikat Pekerja Indonesia, partai politik, universitas dan perusahaan (Sumarwan, 2014). Kelompok formal biasanya terdaftar secara hukum di pemerintah. Kelompok informal adalah kelompok yang tidak memiliki struktur organisasi secara tertulis dan resmi, sifat keanggtaannya tidak tercatat. Kelompok informal biasanya terbentuk karena hubungan sosial, misalnya kelompok bermain badminton, kelompok senam kebugaran, kelompok arisan dan kelompok rukun tetangga. Anggota kelompok informal biasanya berjumlah sedikit dan berinteraksi secara dekat dan tatap muka secara intensif dan rutin.

\section{Kelompok Primer dan Sekunder}

Kelompok primer adalah kelompok keanggotaan yang terbatas, interaksi antar anggota secara langsung tatap muka, memiliki ikatan emosional antar anggota. Anggota kelompok memiliki kesamaan dalam nilai dan sikap. Contoh dari anggota primer adalah keluarga dan kelompok yang memiliki ikatan kekerabatan. Kelompok sekunder memiliki ikatan yang lebih longgar dari kelompok primer, antaranggota kelompok mungkin juga terjadi kontak tatap muka langsung, antar anggoa sekunder bisa berbentuk kelompok formal, seperti asosiasi profesi dan himpunan alumni ataupun 
berbentuk kelompok informal, seperti kelompok arisan, kelompok rukun warga dan teman bermain (Sumarwan, 2014).

\section{Kelompok Aspirasi dan Disosiasi}

Kelompok Aspirasi adalah kelompok yang memperlihatkan keinginan untuk mengikuti norma, nilai, maupun perilaku dari orang lain yang dijadikan kelompok acuannya. Anggota kelompok aspirasi berusaha membuat asosiasi dengan orang lain yang dijadikan acuannya dengan cara bersikap dan berperilaku yang sama dengan orang tersebut. Anak-anak muda sering meniru cara berpakaian para selebriti dari amerika, bahkan meniru perilakunya. Anak-anak muda ini disebut kelompok aspirasi, sedangkan selebriti Amerika sebagai kelompok acuannya.

Kelompok disosiasi adalah seseorang atau kelompok yang berusaha untuk menghindari asosiasi dengan kelompok acuan (Sumarwan, 2014). Contohnya, para anggoat Partai Apel selalu menujukkan ketertiban dalam berdemonstrasi yang sangat berbeda dengan perilaku demo dari kelompok lainnya. Partai Apel berusaha membuat citra yang berbeda dari kelompok lain. Partai Apel bisa dianggap sebagai kelompok disosiasi.

\section{Keluarga}

Keluarga adalah organisasi pembelian terkecil dalam masyarakat dan telah menjadi objek penelitian yang luas (Kotler \& Keller, 2012). Keluarga merupakan lingkungan mikro, yaitu lingkungan yang paling dekat dengan konsumen. keluarga adalah lingkungan dimana sebagian besar konsumen tinggal dan berinteraksi degan anggota-anggota keluarga lainnya. Keluarga menjadi daya tarik pemasar karena keluarga memiliki pengaruh yang besar kepada konsumen. anggota keluarga akan saling mempengaruhi dalam pengambilan keputusan pembelian produk dan jasa (Sumarwan, 2014).

Demikian pula menurut Rizal (2010) yang menyatakan bahwa keluarga memiliki pengaruh yang positif dan signifikan pada keputusan pembelian online. Hal tersebut juga di dukung oleh penelitian Putra (2017) mengenai pengaruh keluarga, kelompok referensi dan persepsi konsumen pada pembelian online smartphone merek Samsung. Ia 
juga menemukan bahwa keluarga memiliki pengaruh yang signifikan pada keputusan pembelian secara online.

\section{Peran dan Status}

Peran terdiri dari aktivitas yang diharapkan dilakukan seseorang menurut orangorang yang ada disekitarnya. Setiap peran tentu saja membawa status yang mencerminkan penghargaan yang diberikan oleh masyarakat. Orang seringkali memilih produk yang menunjukan statusnya dalam masyarakat. Setiap peran akan mempengaruhi perilaku pembelian konsumen (Kotler \& Keller, 2012).

Fitri (2017) mengemukakan bahwa peran dan status merupakan sebuah bagian tak terpisahkan dari individu konsumen yang mana hal tersebut tentu saja mempengaruhi sikap dan keputusan yang diambil termasuk dalam hal melakukan belanja online. Dalam penelitiannya, ia menemukan bahwa peran dan status memiliki pengaruh yang signifikan pada keputusan pembelian secara online. Selain itu pernyataan ini juga didukung oleh Fitriana (2012) bahwa peran dan status memiliki pengaruh yang signifikan pada perilaku konsumen terhadap keputusan pembelian secara online.

\section{METODE PENELITIAN}

Penelitian ini dilakukan kepada pengguna Lazada di Kota Sukabumi yang berusia 20-29 tahun. Metode penelitian yang digunakan oleh peneliti dalam penelitian ini adalah menggunakan metode deskriptif kuantitatif dan metode sampel probability sampling dengan melakukan penyebaran kuesioner sebanyak 116 responden para pengguna Lazada di Kota Sukabumi. Teknik analisis yang digunakan peneliti adalah menggunakan teknik analisis regresi linier berganda, koefisien korelasi ganda dan koefisien determinasi. Untuk pengujian hipotesis peneliti menggunakan uji statistik secara parsial (uji t) dan uji simultan (uji F). 


\section{HASIL PENELITIAN}

\section{Hasil Analisis Regresi Linier Berganda}

Regresi linier berganda digunakan untuk mengetahui pengaruh beberapa variabel yang berkorelasi dengan variabel yang diuji. Hasil uji regresi linier berganda dapat dilihat pada tabel 1 sebagai berikut:

Tabel 1.

Hasil Uji Regresi Linier Berganda

\begin{tabular}{|c|c|c|c|c|c|c|}
\hline \multicolumn{7}{|c|}{ Coefficients $^{\mathrm{a}}$} \\
\hline & \multirow[t]{2}{*}{ Model } & \multicolumn{2}{|c|}{$\begin{array}{c}\text { Unstandardized } \\
\text { Coefficients }\end{array}$} & \multirow{2}{*}{$\begin{array}{c}\begin{array}{c}\text { Standardized } \\
\text { Coefficients }\end{array} \\
\text { Beta }\end{array}$} & \multirow[t]{2}{*}{$\mathbf{t}$} & \multirow[t]{2}{*}{ Sig. } \\
\hline & & B & Std. Error & & & \\
\hline \multirow[t]{4}{*}{1} & $($ Constant $)$ & 13.959 & 1.503 & & 9.284 & .000 \\
\hline & Kelompok Referensi & .555 & .085 & .529 & 6.497 & .000 \\
\hline & Keluarga & .111 & .130 & 0.83 & .856 & .394 \\
\hline & Peran dan Status & -.296 & .132 & -.216 & -.2 .251 & .026 \\
\hline
\end{tabular}

(Sumber: Pengolahan Data, 2019)

Berdasarkan hasil analisis pada tabel 1, didapat persamaan regresi linier berganda untuk tiga predikator yaitu kelompok referensi, keluarga, peran dan status sebagai berikut:

$$
\mathrm{Y}=13.959+0.529 \mathrm{X} 1+0.083 \mathrm{X} 2+(-0.216) \mathrm{X3}
$$

\section{Koefisien Determinasi $\left(\mathbf{R}^{2}\right)$}

Tabel 2.

Hasil Koefisien Determinasi

\begin{tabular}{ccccc}
\hline \multicolumn{5}{c}{ Model Summary } \\
\hline Model & R & R Square & Adjusted $\mathbf{R}$ Square & Std. Error of the Estimate \\
\hline 1 & $.540^{\mathrm{a}}$ & .291 & .272 & 2.619 \\
\hline
\end{tabular}

a. Predictors: (Constant), Peran dan Status, Kelompok, Referensi, Keluarga

(Sumber: Pengolahan Data, 2019)

Hasil tabel 2 di atas menunjukkan bahwa besarnya Adjusted $\mathrm{R}^{2}$ adalah 0,272. Hal ini berarti 27,2\% variasi keputusan pembelian dapat dijelaskan oleh variasi dari 3 variabel independent yakni, kelompok referensi, keluarga serta peran dan status. Kemudian sisanya sebesar $72,8 \%$ merupakan faktor lain yang tidak termasuk kedalam penelitian. 


\section{Uji Signifikasi Secara Simultan (Uji F)}

Tabel 3.

Hasil Uji Simultan (Uji F)

\begin{tabular}{clccccc}
\hline & \multicolumn{7}{c}{ Model Summary } \\
\hline & Model & Sum of Square & Df & Mean Square & F & Sig. \\
\hline \multirow{3}{*}{1} & Regression & 315.906 & 3 & 105.302 & 15.355 & $.000^{\mathrm{b}}$ \\
\cline { 2 - 6 } & Residual & 768.094 & 112 & 6.858 & \\
\cline { 2 - 6 } & Total & 1084.000 & 115 & & \\
\hline a. & Dependent Variable: Keputusan Pembelian & & \\
\hline \multicolumn{2}{l}{ b. } & Predictors: (Constant), Peran dan Status, Kelompok, Referensi, Keluarga \\
\hline (Sumber: Pengolahan Data, 2019)
\end{tabular}

Berdasarkan hasil perhitungan pada tabel 3, diperoleh angka $F_{\text {hitung }} 15,355>$ $F_{\text {tabel }}$ 2,70. Artinya ada pengaruh positif dan signifikan kelompok referensi $\left(X_{1}\right)$, keluarga $\left(\mathrm{X}_{2}\right)$, serta peran dan status $\left(\mathrm{X}_{3}\right)$ terhadap keputusan belanja online pada pengguna Lazada di Kota Sukabumi. Kesimpulan tersebut didukung oleh nilai signifikansinya yakni sebesar $0,00<0,05$ yang dianggap signifikan.

\section{Uji Signifikasi Secara Parsial (Uji t)}

Tabel 4.

Hasil Uji Parsial (Uji t)

\begin{tabular}{|c|c|c|c|c|c|c|}
\hline \multicolumn{7}{|c|}{ Coefficients $^{\mathrm{a}}$} \\
\hline & \multirow{2}{*}{ Model } & \multicolumn{2}{|c|}{$\begin{array}{c}\text { Unstandardized } \\
\text { Coefficients }\end{array}$} & \multirow{2}{*}{$\begin{array}{c}\begin{array}{c}\text { Standardized } \\
\text { Coefficients }\end{array} \\
\text { Beta }\end{array}$} & \multirow[t]{2}{*}{$\mathbf{t}$} & \multirow[t]{2}{*}{ Sig. } \\
\hline & & B & Std. Error & & & \\
\hline \multirow[t]{4}{*}{1} & $($ Constant $)$ & 13.959 & 1.503 & & 9.284 & .000 \\
\hline & Kelompok Referensi & .555 & .085 & .529 & 6.497 & .000 \\
\hline & Keluarga & .111 & .130 & 0.83 & .856 & .394 \\
\hline & Peran dan Status & -.296 & .132 & -.216 & -.2 .251 & .026 \\
\hline
\end{tabular}

a. Dependent Variable: Keputusan Pembelian

(Sumber: Pengolahan Data, 2019)

Berdasarkan hasil data pada tabel 4, diketahui bahwa ada pengaruh kelompok referensi terhadap keputusan pembelian, dimana angka $t_{\text {hitung }}$ yaitu sebesar 6,497 ( $>t_{\text {tabel }}$ $=1,981)$ dengan nilai signifikansi sebesar $0,00<0,05$ yang di anggap signifikan. Adapun pada keluarga, angka $t_{\text {hitung }}$ adalah sebesar 0,856 dengan nilai signifikansi sebesar 0,394 yang dianggap tidak signifikan. Selanjutnya pada peran dan status, angka

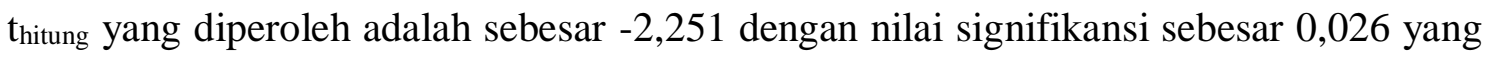
dianggap signifikan. Artinya ada pengaruh peran dan status terhadap keputusan pembelian, namun sifat pengaruhnya adalah negatif. 


\section{PEMBAHASAN}

Berdasarkan hasil penelitian, peneliti menemukan bahwa kelompok referensi, keluarga,serta peran dan status mampu menggambarkan dan memiliki kontribusi pada keputusan pembelian online pengguna Lazada di Kota Sukabumi. Kelompok referensi merupakan salah satu faktor yang paling kuat memperngaruhi perilaku konsumen, yakni dalam membentuk keputusan pembelian secara online. Hal ini sejalan dengan hasil penelitian Apriyandani et al., (2017) bahwa variabel kelompok referensi berpengaruh signifikan terhadap keputusan pembelian. Temuan ini diperkuat dengan pendapat Suryani (2008) bahwa kelompok referensi merupakan individu atau kelompok yang dijadikan rujukan yang mempunyai pengaruh nyata bagi individu atau digunakan sebagai acuan dalam membentuk respons afektif dan respon kognitif serta melakukan perilaku.

Berbeda dengan pengaruh kelompok referensi, keluarga tidak berpengaruh terhadap keputusan pembelian online pada pengguna Lazada di Kota Sukabumi. Hal ini berlawanan dengan hasil temuan Debora et al., (2014) dan Syifa et al., (2014) bahwa variabel keluarga berpengaruh signifikan terhadap keputusan konsumen. Selanjutnya pada pengaruh peran dan status, hasil menunjukkan bahwa variabel ini berpengaruh terhadap keputusan konsumen, namun dengan pengaruh yang bersifat negatif. Menurut Kotler (2005) kedudukan seseorang pada masing-masing kelompok dapat ditentukan berdasarkan peran dan status. Peran adalah kegiatan yang diharapkan akan dilakukan oleh seseorang, dimana masing-masing peran tersebut akan menghasilkan status. Orangorang cenderung memilih produk yang dapat memperlihatkan peran dan status mereka di masyarakat.

\section{SIMPULAN}

Gambaran kelompok referensi, keluarga, serta peran dan status merupakan sebagian faktor yang mempengaruhi keputusan pembelian secara online yang dilakukan oleh pengguna Lazada di Kota Sukabumi. Ketiga variabel tersebut mampu menggambarkan dan memiliki kontribusi pada keputusan pembelian online pengguna Lazada, meskipun sebagian besar dipengaruhi oleh faktor-faktor lain yang tidak termasuk dalam penelitian. 
Kelompok referensi merupakan salah satu faktor yang paling kuat memperngaruhi perilaku konsumen, khususnya dalam membentuk keputusan pembelian secara online. Hasil analisis menunjukkan bahwa kelompok referensi memiliki pengaruhi yang signifikan terhadap keputusan pembelian online pada pengguna Lazada di Kota Sukabumi.

Keluarga merupakan lingkungan sosial yang paling dekat dengan konsumen. Hasil analisis menunjukkan bahwa variabel keluaga tidak berpengaruh terhadap keputusan pembelian online pada pengguna Lazada di Kota Sukabumi. Adapun pada variabel peran dan status dalam penelitian ini menunjukkan adanya pengaruh terhadap keputusan pembelian, namun dengan arah yang negatif.

\section{DAFTAR PUSTAKA}

Apriyandani, H., Yulianto, E., \& Sunarti, S. (2017). Pengaruh Gaya Hidup dan Kelompok Referensi terhadap Keputusan Pembelian (Survei Mahasiswa S1 Fakultas Ilmu Administrasi Angkatan 2014 dan 2015 Universitas Brawijaya Malang yang Membeli dan Menggunakan Smartphone iPhone). Jurnal Administrasi Bisnis (JAB), 50(2), 180-189

Asosiasi Pengguna Jaringan Internet Indonesia. (2017). Survei APJII : Penetrasi Internet di Indonesia Capai 143 Juta Jiwa. https://apjii.or.id/content/read/104/348/BULETIN-APJII-EDISI-22---Maret2018

CNBC Indonesia. (2018). YLKI: Lazada Paling Banyak Dikeluhkan Konsumen Selama 2017. https://www.cnbcindonesia.com/news/20180119113118-4-1979/ylkilazada-paling-banyak-dikeluhkan-konsumen-selama-2017

Databoks.katadata.co.id. (2018). Berita Pengguna E-Commerce Terbanyak di Triwulan Keempat Tahun 2018. https://databoks.katadata.co.id/datapublish/2018/012/18/lazada-e-commercepaling-banyak-pengunjung-tw-iv-2018]

Debora, R., Sulistyowati, L., \& Musfar, T. F. (2014). Pengaruh Keluarga dan Kelompok Referensi terhadap Keputusan Konsumen Membeli Kosmetika Khusus Pria Merek Garnier Men (Studi Kasus di Pekanbaru). Jurnal Online Mahasiswa Fakultas Ekonomi Universitas Riau, 1(2), 1-11

Fitri, A. T. (2017). Pengaruh Peran dan Status serta Konsep Diri Konsumen terhadap Keputusan Pembelian Online pada Chandra Super Store Mall Lampung. Lampung: Repository Unila

Fitriana, D. (2012). Pengaruh Peran dan Status pada Perilaku Konsumen Dalam Melakukan Belanja Secara Online. Skripsi. Universitas Indonesia

Globalwebindex. (2018). Trends 18, The Trends to Know for 2018. https://www.globalwebindex.com/reports/trends- 18 
Kotler, P. \& Keller, K.L. (2012). Manajemen Pemasaran Jilid I Edisi ke 12. Jakarta: Erlangga

Kotler, P. (2005). Manajemen Pemasaran, Jilid 1 dan 2. Jakarta: PT. Indeks Kelompok Gramedia

Mauludiyahwati, S. (2017). Pengaruh Kepercayaan, Keamanan, Kualitas Pelayanan dan Persepsi Risiko Menggunakan E-Commerce terhadap Keputusan Pembelian Online (Survei pada Konsumen www.lazada.co.id). S1 Thesis. Universitas Negeri Yogyakarta

Putra, F. D. U. (2017). Analisis Pengaruh Keluarga, Kelompok Rujukan dan Persepsi Konsumen terhadap Keputusan Pembelian Smartphone Android Merek Samsung (Studi Kasus pada Mahasiswa Universitas Sanata Dharma Yogyakarta). Skripsi. Universitas Sanata Dharma Yogyakarta

Rizal, A. (2010). Analisis Pengaruh Grup Referensi dan Keluarga terhadap Keputusan Pembelian Ponsel Qwerty terhadap Mahasiswa UIN Syarif Hidayatullah Jakarta. Skripsi. UIN Syarif Hidayatullah

Schiffman, L. G., \& Kanuk, L. L. (2010). Consumer Behaviour (10th ed). New Jersey: Pearson Prentice Hall

Sumarwan, U. (2014). Perilaku Konsumen Teori dan Penerapannya Dalam Pemasaran. Bogor: Ghalia Indonesia

Suryani, T. (2008). Perilaku Konsumen. Yogyakarta: Graha Ilmu

Syifa, S., Sulistyowati, L., \& Musfar, T. F. (2014). Pengaruh Keluarga dan Kelompok Referensi terhadap Keputusan Konsumen Membeli Kosmetika Khusus Pria (Studi Kasus Merek Nivea Men di Kota Pekanbaru). Jurnal Online Mahasiswa Fakultas Ekonomi Universitas Riau, 1(2), 1-15 